\title{
Green Synthesis and Optimization of Zinc Oxide Quantum Dots Using the Box-behnken Design, With Anticancer Activity Against the MCF-7 cell line
}

\section{R. Mary Nancy Flora}

Arunai Engineering College

\section{S. Palani}

Arunai Engineering College

J. Sharmila

St.Joseph's College of Engineering

M.CHAMUNDEESWARI M ( $\nabla$ chamundeeswari@gmail.com)

SJEC: St Joseph Engineering College https://orcid.org/0000-0001-6449-8678

\section{Research Article}

Keywords: Quantum dots, Catharanthus roseus, Nanobiocomposite, Anticancer activity, Aloe vera, MTT assay

Posted Date: November 12th, 2021

DOI: https://doi.org/10.21203/rs.3.rs-1068337/v1

License: (9) This work is licensed under a Creative Commons Attribution 4.0 International License. Read Full License

Version of Record: A version of this preprint was published at Applied Physics A on March 31st, 2022. See the published version at https://doi.org/10.1007/s00339-022-05466-4. 


\section{Abstract}

A green strategy and cost-effective approach was adapted to prepare Zinc oxide quantum dots (ZnOQDs) for biomedical applications. The prepared ZnO-QDs may hold great promise as sensing scanners for diagnostics and therapy, as demonstrated in our current study. Zinc Sulphate, Azadirachta indica, and Catharanthus roseus leaves extract were used to synthesis a novel natural Zinc oxide bionanocomposite (ZnO-BC) and used as a precursor to prepare ZnO-QDs by microwave-assisted technique. The ZnO-BC was characterized by SEM-EDX, FTIR, XRD, Zeta potential and particle size analysis. The optical properties of QDs were investigated using UV and PL spectrophotometers. Experimental factors like the concentrations of ZnO-NPs, $C$. roseus and $A$. verawere evaluated using Box-Behnken design (BBD). MTT and haemolysis assay was performed using ZnO-BC and ZnO-QDs. Maximum absorbance observed at optimized values of $0.5 \% \mathrm{ZnO}-\mathrm{NPs}, 1 \mathrm{~g}$ A.vera gel and $0.5 \mathrm{ml}$ C.roseus leaf extract of ZnO-QDs against BBD. There was decreased viability rate, ranging from $60-15 \%$ for $0.5 \mathrm{mg} / \mathrm{ml} \mathrm{ZnO-BC}$ and $45-5 \%$ for 5 $\mathrm{mg} / \mathrm{ml} \mathrm{ZnO-QDs}$ which revealed a tenfold decrease in cell viability with less concentration scale for $5 \mathrm{mg} / \mathrm{ml}$ of ZnO-QDs when compared with that of $0.5 \mathrm{mg} / \mathrm{ml} \mathrm{ZnO-BC}$. Also, hemolysis test shows that the hemolysis ratio was below $0.5 \%$, indicating non-haemolysis of ZnO-QDs. cellular morphology by results was supported by phase-contrast microscopy images. A good biocompatibility and high anticancer activity was noticed for ZnO-QDs when compared to $\mathrm{ZnO}-\mathrm{BC}$ and provide versatile applications in the field of Nano biomedicine.

\section{Introduction}

Semiconductor carbon quantum dots of low-dimensional $(<10 \mathrm{~nm})$ has got notable consideration for possible use in medical application such as diagnosis and treatment where larger nanoparticles $(>10 \mathrm{~nm})$ are ineffective [1]. Quantum dots (QDs) have gained broad thought for their dominating properties like low poisonousness, small sizes, water solvency, biocompatibility and extraordinary photoluminescence properties [2]. Quantum dots (QDs) is a family of carbonaceous nanostructures and one of the emerging nanomaterial [3]. QDs are characterized as nanoparticles with molecule size more modest than its excite on Bohr radius which is around $<20 \mathrm{~nm}$ [4]. Additionally, QDs can be simply synthesized with low-cost methods that putaside acomplex, toxic, time-consuming and high-cost synthesis methods [5]. Different expansive range of applications like solar cells, chemo-sensor, drug delivery, biosensor, cell imaging and catalysis [6-11] have been incorporated using carbon quantum dots (CQDs) because of their distinct physical and chemical properties like water solubility, brilliant fluorescence, non-toxicity and biocompatibility. Then again, the capability of utilizing CQDs in different applications expands the need to synthesis them on an industrial scale which is harmless to the ecosystem and green cycles. To avoid the issues of the chemical method of nanoparticle preparation an eco-friendly approach was adopted using plant material which is a green strategy [12]. Heaps of literature surveys have demonstrated benefits in green strategies which are natural cost-effective, environmentally friendly, and simple to increase much of the time, the shortfall of compound chemicals, poisonous foreign substances and utilizing low-valued precursors [13-15]. Other than these there are numerous possible effective molecules 
in the plant interceded synthesis of nanoparticles which is appropriate for a wide scope of biomedical applications [12].

A couple of designed strategies of QDs have been accounted, for example, pyrolysis, aqueous carbonization strategy, microwave radiation, laser removal, curve release, and plasma treatment [16-21]. Among them, microwave strategy is considered as a fundamental and green engineered approach due to its possible interaction, utilization of fluid medium and arrangement of QDs with better quantum yield. Also, Microwave radiation was thought to be the best, cheapest, and quickest way to create fluorescent QDs, on the grounds that it doesn't use a lot of equipment, is not difficult to perform, and saves time.Microwave-assisted heating method does not require any firm reaction conditions and is easy to operate compared to other synthetic methods. It is a one-step method of preparation and stabilization of QDs.Therefore, making it an economically and environmental friendly method which could be used in large scale production of fluorescent QDs [22].

Metal and metal oxide nanomaterials have demonstrated critical restorative effects in scientific progress [23] because these nanoparticles have a high surface-to-volume ratio, which allows for better interaction with cancer cells and microscopic organisms [24]. Among these, $\mathrm{ZnO}$ is a major semiconductor material with a direct wide band gap and high directivity at $25^{\circ} \mathrm{C}$, other than because of huge excitation on restricting energy of $60 \mathrm{meV}$. The way that $\mathrm{ZnO}$ has solid pharmacological properties which increment its utilization in medical services regions, for example, anticancer, antimicrobial, and cancer prevention agents [25] so preparation of ZnO nanomaterial using metals like Zinc can be added with the plant-based synthesis of $\mathrm{ZnO}$ quantum dotsandwould pave a good way to fight against cancer in the forthcoming generations.

Among different cancers, Breast cancer is one of the most widely recognized reasons for the cancer diseasein females in the entire world (WCR, 2008). $23 \%$ of all as of late happening cancers in ladies called breast cancer have been noticed worldwide and $13.7 \%$ has been addressed as death due to cancer because of breast cancer in both genders [26]. Option and necessary medications are at present considered to assume an arising part in the prevention of cancer. Plant-based materials from nature are inside simple reach and are an amazingly encouraging technique for chemo-prevention to impede the advancement of cancer in humans [27]. An outcome, semiconductor nanoparticles/quantum dots (QDs) of low-dimensional have obtained incredible consideration in cancer treatment using nanotechnology [28].

Optimization of various factors over evaluating independent variable and responses relationship is given by Response surface methodology (RSM) [29,30]. This technique has been successfully applied in a variety of biotechnology fields, as well as some new studies for the green synthesis of carbon quantum dots [31, 32]. RSM was used for the optimization of variables for biological synthesis of ZnO-QDs was performed.

An enormous number of late written works uncovered that thoughtful and simple fabrications of QDs for various cancer investigations and also other biological applications have taken serious efforts. H.S. 
Zavareh et al., for example, reported that carbon quantum dots made of Chitosan were used as an anticancer medication to deliver 5-fluorouracil [9], x. li et al. reported that a carbon quantum dot was used for combined photodynamic-chemotherapy examination of cancer cells [33], Ganesan Muthusankar et al. formed a productive probe for the simultaneous determination of anticancer and antibiotic drugs using nitrogen-doped carbon quantum dots implanted $\mathrm{CO}_{3} \mathrm{O}_{4}$ with multiwall carbon nanotubes. [34]. E.S.M. Cutrim et al. prepared and characterized nanoconjugate based QDs and an in vitro anticancer performance was checked [35]. Zinc oxide QDs were prepared for the evaluation of breast cancer, were reported by Zahra Fakhroueian et al [36]. Also a chitosan-encapsulated ZnO quantum dot was designed for in vitro drug delivery response by Q. Yuan et al [37]. Accordingly, these research works get the impact of the green way of QDs synthesis with compound interactions of useful hetero atom doping, a gathering of an antecedent, which gives the way to solid arrangement of quantum yield. Nature reliably gets additional thought from material scientists considering its unlimited focal point for making novel materials with less biological effect. To enrich biomass firm QDs, alternate bio-waste/plant materials were used as regular forerunners to set up the quantum dot material [38-39]. Because of their exceptional fluorescence and identifying properties, biomass-derived QDs have received a lot of attention from scientists as a candidate material for semiconductor quantum dots and other fluorescent regular components.

Catharanthus roseus, is additionally notable as Madagascar, C. roseus is a type of blossoming plant having a place with the family Apocynaceae. C. roseus originated on the Indian Ocean island of Madagascar, and it is now widely distributed in Australia, China, South America, Indonesia, and North America. The plant's leaves are abundant in monomeric indole alkaloids such as vindoline and catharanthine, which have remarkable therapeutic properties such as anticancer, antibacterial, antifungal, anti-microbial, cancer prevention agent, wound healing, and antiviral activities. Likewise, plant leaf concentrates are a rich source of chemically significant terpenoid indole alkaloids, and it is currently used in the semi-union of two anticancer medications (vinorelbine and vinflunine) in pharmaceutical companies [40-41]. Thus, it is profoundly alluring to set up a proficient QD from C.roseus leaves without the guide of solid corrosive dissolvable, surface passivation reagent, as well as a complicated posttreatment procedure [38].

By taking into consideration of the above facts, a novel method that combines zinc oxide bionanocomposite derived ZnO-QDs was synthesized using extract of $C$. Roseusand Aloe vera, which was then converted to QDs and assessment of their biological activities are reported. C. roseus leaves were selected since it contains vinblastine and vincristine. Chemical constituents of $C$. roseus are expected to play an important role in the development of (ZnO-QDs). Interestingly, we exhibit the anticancer activity of $C$. roseus derived ZnO-QDswhich are represented in scheme 1.The connection between the biological activity of cancer cells in anticancer activity and haemolytic activity of low dimensional green synthesized QDs are the major highlights of this work. The results of commercial products and control samples were compared. We have primarily engagedone pot approach to prepare QDs without any passivation agent by simple microwave-assisted technique which is a green synthetic and eco-friendly 
approach applying $C$. roseus leaves as carbon origin. Critically, our outcomes uncovered that $C$. roseus based QDs have minuscule molecule size, low harmfulness, solid fluorescence and biocompatibility, which have been utilized in cell imaging of MCF 7 cell lines. C.roseus based (ZnO-QDs) in ongoing has great likely application for biomedical and environmental pollution.

\section{Materials And Methods}

\subsection{Reagents and Chemicals}

C. roseus (vinca rosea) leaves were collected from nearby local farms in Tiruvannamalai, Neem leaves and Aloe vera was gathered from Arunai Engineering college campus, Tiruvannamalai. Other chemicals like Pharmaceutical grade Zinc Sulphate $\left(\mathrm{ZnSO}_{4}\right)$ were purchased from Hi-tech enterprise Pvt Ltd, Chennai, Sodium hydroxide and Glacial acetic acid were purchased from Qualiens Chennai, India.

\subsection{Synthesis of ZnO-NPs using neem (Azadirachta indica) leaf extract}

Neem leaves of around $30 \mathrm{~g}$ were completely washed using distilled water and were dried and crushed. 1 $L$ distilled water was added to this and bubbled for around $15 \mathrm{~min}$. The extract was obtained by filtering with Whatman No.1 filter paper with pore size of $35 \mu \mathrm{m}$. A pale yellowish colored solution was obtained. An aqueous solution of Zinc sulphate $\left(\mathrm{ZnSO}_{4}\right)$ of $1 \mathrm{mM}$ and Azadirachta indica aqueous leaf extract was utilized for the preparation of ZnO NPs. $20 \mathrm{ml}$ of Azadirachta indica leaf extract was added drop by drop to $80 \mathrm{ml}$ of $1 \mathrm{mM} \mathrm{ZnSO} 4$ aqueous solution [42-43]. It was stirred in a magnetic stirrer for about 24 hours at $37^{\circ} \mathrm{C}$ until a pale white paste formed. This paste was transferred to a porcelain crucible pot and warmed in a heater at $350^{\circ} \mathrm{C}$ for 1 hour. For the synthesis of $\mathrm{ZnO}-\mathrm{BC}$, the obtained pale white colored powder of ZnO NPs was used.

\subsection{Preparation of bionanocomposite (ZnO-BC) using $C$. Roseusextract}

Prior to preparation, the gathered $C$. roseus leaves, which are high in carbon source, were thoroughly washed in deionized water, hacked into small pieces, and dried at room temperature. $50 \mathrm{~mL}$ of deionized water was mixed with $0.5 \mathrm{~g}$ of $C$. roseus leaves and bubbled for 15 minutes. From then on, it was permitted to reach room temperature. The pale yellowish arrangement was obtained and separated using a $0.45 \mu \mathrm{m}$ layer channel to remove unreacted natural moieties and unwanted large particles [38]. $0.5 \%$ $\mathrm{ZnO}$ NPs were dispersed in $1 \mathrm{~g}$ of Aloe vera gel for $2-3 \mathrm{~h}$ and it was sonicated for $5 \mathrm{~min}$ at $50{ }^{\mathrm{D}} \mathrm{C}$. After that, $0.5 \mathrm{ml}$ of $C$. Roseus leaf extract was added dropwise and stirred for 24 hours to achieve a homogeneous mixture. At last, the precipitate was dried at $50{ }^{\square} \mathrm{C}$ overnight in the oven. A brownish-black powder of ZnO$\mathrm{BC}$ was formed and used as a natural carbon source for the synthesis of ZnO-QDs. 


\subsection{Biogenic preparation of ZnO-QDs from $C$. roseus leaves from ZnO-BC}

A one-pot synthesisof microwave assistedprocedure was chose to blend the QDs from the $C$. roseus leavesextract prepared from ZnO-BC as a natural carbon source. $20 \mathrm{ml}$ of $5 \mathrm{mg} / \mathrm{ml} \mathrm{ZnO-QDs}$ was prepared using $0.5 \mathrm{mg} / \mathrm{ml} \mathrm{ZnO-BC}$ and suspended in distilled water of $30 \mathrm{ml}$ keptunder magnetic stirrer for $10 \mathrm{~min}$. The ZnO-BC suspension was then exposed to microwave for $15 \mathrm{~min}$ and then at $8000 \mathrm{rpm}$, it was centrifuged for $10 \mathrm{~min}$ to assist ZnO-QDs synthesis. The supernatant was collected and observed under UV light trans-illumination for fluorescence property and stored for further applications. Thisentire process for the synthesis of ZnO-QDs is also shown in scheme 1.

\section{Characterization Studies}

The UV absorption (Perkin Elmer Lambda 9) was carried out to find the excitation wavelength. Zeta potential and Particle size (HORIBA) estimation tests were carried out by using a nanocomposite. The surface morphology and elemental analysis of $\mathrm{ZnO}-\mathrm{BC}$ were examined using a scanning electron microscope (SEM; JEOL JSM 6360) coupled with an energy-dispersive X-ray (Oxford Instruments, INCApentaFETx3). To investigate the effect of organic species in plant extract on ZnO-BC, FT-IR spectrum (IR prestige 21, Shimadzu) was used. X-ray diffraction (XRD) was used to examine the crystalline nature of the as-prepared ZnO-BC (Bruker D8 Advance).

\subsection{Cell culture and MTT assay}

MCF7 (breast cancer cell line) was plated independently in 96 well plates with 1104 cells/well concentration in EMEM media with $1 \mathrm{X}$ solution of Antibiotic Antimycotic and $10 \%$ foetal bovine serum (Himedia, India) with $5 \% \mathrm{CO} 2$ at $37^{\circ} \mathrm{C}$ in $\mathrm{CO}_{2}$ incubator. The cells were washed with $200 \mathrm{~L}$ of $1 \mathrm{X}$ PBS before being treated with different test concentrations of $5 \mathrm{mg} / \mathrm{ml}$ prepared ZnO-QDs and $0.5 \mathrm{mg} / \mathrm{ml}$ prepared $\mathrm{ZnO}-\mathrm{BC}$ in serum-free media and incubated for 24 hours. Toward the end of the treatment period, the medium was suctioned from the cells. The prepared $0.5 \mathrm{mg} / \mathrm{mL}$ MTT with 1 X PBS was incubated at $37 \mathrm{C}$ for about 4 hours in a $\mathrm{CO} 2$ incubator. After incubation, the MTT-containing medium was removed from the cells and washed with $200 \mathrm{~L}$ of PBS. The crystals were disintegrated and completely blended with $100 \mathrm{~L}$ of Dimethyl sulfoxide (DMSO) [44, 45]. At $570 \mathrm{~nm}$, there was a development of intensified colour where the formazan dye turned purple-blue. A microplate was used to calculate absorbance at $570 \mathrm{~nm}$.

\subsection{Morphological analysis in MCF-7 cell line}

Inverted phase-contrast microscope at 20X magnification (OLYMPUS LS CKX 31) was used to see the macroscopic and microscopic changes that occurred in MCF-7 cells which were exposed to different doses of $500-25 \mu \mathrm{g} / \mathrm{ml}$ of ZnO-BC $(0.5 \mathrm{mg} / \mathrm{ml})$ and $3.125-50 \mu \mathrm{g} / \mathrm{ml}$ of ZnO-QDs $(5 \mathrm{mg} / \mathrm{ml})$.

\subsection{Haemocompatability assay}


To determine the toxic effect of ZnO-QDs with red blood cells (RBC) Haemolytic assay was carried out using a whole blood sample. Fresh blood was collected using a disposable syringe and stored in a centrifuge tube containing EDTA to prevent the blood from clotting. The blood sample was diluted using $1 \times$ PBS buffer in equal volume [46]. To $0.5 \mathrm{ml}$ of blood, $5 \mathrm{mg} / \mathrm{ml} \mathrm{ZnO-QDs} \mathrm{of} \mathrm{the} \mathrm{prepared} \mathrm{sample} \mathrm{was}$ added in different concentrations 50 to $250 \mu \mathrm{l}$ which an increment of $50 \mu \mathrm{l}$ in an Eppendrofftube, 3 hincubation time was given with agitation for a few minutes after every $1 \mathrm{~h}$. Then the sample was centrifuged for $10 \mathrm{~min}$ at $1600 \mathrm{rpm}$ and then removed the supernatant and the optical density was checked at $540 \mathrm{~nm}$.

\subsection{Statistical Analysis for anticancer activity}

Analysis of Variance (ANOVA) and Tukey's test was applied to know the high range measurable domain of difference between mean values of cell viability of different cell lines treated with ZnO-QDs Vs. ZnO$B C$. All tests were carried out in triplicate, and the results were reported as mean $\pm S D$ [47]. Hence, from the results, statistical significance with $p$ values $<0.05$ was contemplated.

\subsection{Data analysis of Box-Behnken design for ZnO-QDs}

The Box-Behnken design was used in this study to estimate the synergy of the factors for a concentration of ZnoNps (X1), A.vera (X2), and C.roseus (X3) on the absorbance response of ZnO-QDs. The range and levels of the variables were observed. For the prepared design, 17 run was performed for the desired factors and levels in this study. Design Expert- 13 software was used to analyze the variables of response surfaces inside the experimental scope. As a result, three additional confirmation experiments were carried out to validate the statistical experimental statistics. Finally, UV-VIS and PL examinations were performed in derived optimum conditions after $\mathrm{ZnO}$-QDs biosynthesis to demonstrate the reasonableness of the BBD.

\section{Results And Discussion}

\subsection{Visual observation of ZnO-QDs}

With the developing interest in green synthesis and to restricting the utilization of toxic chemicals and nanoparticles of heavy metals, the improvement of organic, biomimetic, and biochemical methodologies for formingnanoparticles was wanted. Green strategies for nanoparticles synthesis are more invaluable than physicochemical techniques because of theireco-friendly and non-toxic nature. Fig. 1 shows the visual observation of prepared ZnO-QDs from C.roseus leaf extract by microwave-assisted method. The commercial $\mathrm{ZnO}$ and synthesized $\mathrm{ZnO}$ were used as a control sample in order to prove the fluorescence property emitted by ZnO-QDs on exposure to UV light. The presence of a good fluorescence effect was noticed in ZnO-QDs (1c) prepared from ZnO-BC alone when compared to control samples a) commercial $\mathrm{ZnO}$ and b) synthesized $\mathrm{ZnO}$. Apart from this the prepared $\mathrm{ZnO}-\mathrm{BC}$ and $\mathrm{ZnO}-\mathrm{QD}$ s were characterized using XRD, FT-IR, SEM -EDX, UV spectroscopy, PL spectroscopy, Particle size analyzer and Zeta potential analysis. 


\subsection{UV and Photoluminescence spectrum}

UV spectroscopy was finished to break down the optical properties of processed ZnO-QDs (bare) including ZnO-QDs (C.roseus) and shown in Fig. 2 (a) [38]. The UV range revealed broad absorption peaks at 270 and $360 \mathrm{~nm}$, confirming the $\pi-\pi^{\star}$ and $n-\pi^{*}$ electronic changes caused by the presence of $\mathrm{C}-\mathrm{O}$ and $\mathrm{C}-\mathrm{C}$ functional groups in $\mathrm{ZnO}-\mathrm{QDs}$. To impress the properties of Photoluminescence of QDs exhaustively, an excitation frequency was adjusted from 270 to $350 \mathrm{~nm}$ with period of $10 \mathrm{~nm}$. The most extreme outflow of $500 \mathrm{~nm}$ and $550 \mathrm{~nm}$ was seen at excitation frequency of $330 \mathrm{~nm}$ for ZnO-QDs (bare) and ZnO-QDs of C.roseus (displayed in Fig. 2b). This wavelength confirms that the ZnO-QDs prepared out of C.roseusleaf extract showed high intensity when compared to that with ZnO-QDs (bare). It was seen that the extract of natural material acts as penetrating and reducing agents to synthesize quantum dots. The presence of greenish-blue color was seen with the naked eye due to the presence of high intensity which confirms the presence of good optical property [48].

\subsection{X-ray diffraction analysis}

The calculated crystalline size of the ZnO-BC was about $26.974 \mathrm{~nm}$ (Bruker D8 Advance).The obtained XRD graph was given in Fig. 3 and a broad diffraction peak centered at $25.974^{\circ}(2 \theta)$ was witnessed. This implies that the synthesized ZnO-BC was amorphous [42].

\subsection{FT-IR spectrum}

The explained peaks of the FT-IR spectra are shown in Fig. 4 as proof of the synthetic usefulness of ZnOBC. The expansive peaks of around $3547 \mathrm{~cm}-1$ are traced to the extending of $-\mathrm{OH}$ affirms alcoholic, phenolic, and carboxylic structures and the peak at 2230-2018 cm-1 was compared to the aliphatic and aromatic $\mathrm{C}-\mathrm{H}$ stretches of $\mathrm{ZnO}-\mathrm{BC}$. Besides, it's $\mathrm{C}=0$ group was identified by the peaks at $2342 \mathrm{~cm}-1$ and $1101 \mathrm{~cm}-1$. Peaks at $1142 \mathrm{~cm}-1$ confirm the $\mathrm{C}=\mathrm{C}$ bond, and a peak at at $1613 \mathrm{~cm}-1$ confirms the $\mathrm{C}-\mathrm{N}$ bond. Besides, the peaks situated at $984-631 \mathrm{~cm}-1$ could be allocated to the $\mathrm{C}-\mathrm{O}$ and $\mathrm{C}-\mathrm{C}$, which was recorded as a single band $[38,12]$.

\subsection{Scanning electron microscopy and energy dispersive X- ray analysis}

The morphological components of ZnO-BC saw under SEM showed that the particle size went between $80 \mathrm{~nm}-139 \mathrm{~nm}$ with between molecule distances. The state of ZnO-BC was seen to be spherical (Fig. 5a). The EDX spectra showed that the combination of zinc and oxygen components in ZnO-BC was $12.81 \%$ and $50.67 \%$ respectively (Fig. 5 b). The adsorbed constituents of the leaf extracts are represented by the carbon peak in the spectrum [49]. Carbon is the primary chemical constituent in both the $C$. roseus and $A$. Vera leaf chemical structures, and it is abundant in leaf extracts. The EDX spectrum demonstrates the formation of particles via bioreduction of plant leaf extracts, confirming the presence of $\mathrm{ZnO}$ in $\mathrm{ZnO}$ BC. 


\subsection{Particle size distribution and Zeta potential measurements}

The stability of ZnO-BC was measured through Particle size distribution and Zeta potential (Zetasizer NanoZS, Malvern Instruments, UK). The measurements were made by taking the average of three repeated measurements. The $\mathrm{ZnO}-\mathrm{BC}$ exhibited a generally narrow particle size distribution with a mean particle size of 557nm which is illustrated in Fig. 6a [50].Zeta potential provides the idea about surface charges of about $-2.7 \mathrm{mV}$ indicating that the presence of $\mathrm{ZnO}-\mathrm{BC}$ dispersed or blended with zinc sulphate, A.vera and C.roseus which affected the $\mathrm{ZnO}-\mathrm{BC}$ size and their surface charges. The stability of the biocomposites suggestion was given and the value of zeta potential lies within the stable low range which infers that the green $\mathrm{ZnO}-\mathrm{BC}$ is unstable in an aqueous medium [49]. Therefore, ZnO-BC may have accumulation due to residual surfactants and may act as more stable components (Fig. 6b).

\subsection{Optimization and confirmation experiments of ZnO-QDs using RSM}

Optimization of variables concentration for the synthesis of ZnO-QDs was achievedthrough BoxBehnken design (BBD) of experiments. BBD was particularly preferredforaccurate estimates, low-cost and high-qualityproducts developmentwith specific desired features demanded in researches. The data of absorbance of ZnO-QDs was analysed using analysis of variance (ANOVA), regression coefficients, and regression equation using Design Expert-13 software. The Absorbance as a contemporary function of the concentration of ZnO NPs, $A$. vera and $C$. roseus is represented in polynomial equation shown as below in equation (1)

$$
Y=\beta_{0} \sum_{i=1}^{3} \beta_{i} x_{i}+\sum_{i=1}^{3} \beta_{i i} x_{i}^{2}+\sum_{i=1}^{3} \sum_{j=i+1}^{3} \beta_{i j} x_{i} x_{j} \rightarrow(1)
$$

We can learn from the analysis that the model's coefficient of determination (R2) is 0.9337 , indicating that the model is significant. The model F-value is 10.95 , indicating that the model is suitable for addressing the genuine connections among the selected factors. Because the P-values are less than 0.05, the independent factors $A, B$, and $C$, as well as the quadratic term of $A B, A C, B C$, and $A^{2}, B^{2}, C^{2}$, have a large effect on the absorbance of the obtained ZnO-QDs. The 2D form plots and the 3D response surfaces of the reactions using Eq. (1) for the QDs absorbance are displayed in Fig. 7. To demonstrate the intuitive effects of autonomous factors on responses, one variable was kept constant while the other two shifted within a specific range. The shapes of response surfaces and contour plots revealed the extent of interaction between various factors and its nature [29]. Less conspicuous or negligible connections are shown by circular contour plots, whereas relatively notable interactions are generally shown by elliptical shape plots (Fig. 8) illustrating that the concentration of ZnO NPs, $A$. vera and $C$. roseus significantly influences the absorbance of the as-prepared ZnO-QDs, while the circular nature inFig. $8 \mathrm{~b}$ demonstrates that the absorbance is not affected by the concentration value of precursor solution significantly. 
Graphical optimizations by Design-Expert software provide optimum conditions for the microwave method. Thinking about the two expenses and effectiveness, the optimum operating parameters were observed to be $\mathrm{A}=1 \mathrm{ml}, \mathrm{B}=1 \mathrm{~g}$ and $\mathrm{C}=0.5 \mathrm{ml}$. That is, the concentration of ZnO-NPs, $A$. vera and $C$. roseus values was fixed at $1 \mathrm{ml}, 1 \mathrm{~g}$ and $0.5 \mathrm{ml}$, separately. Affirmation tests were conducted in three replicates under these conditions. The observed mean absorbance was found to be generally consistent with the expected qualities. The QDs obtained had a high absorbance up to $330 \mathrm{~nm}$, which corresponds to the PL properties of the synthesised ZnO-QDs.

\subsection{MTT assay}

MTT assays were used to compare the cytotoxicity of ZnO-QDs to ZnO-BC. A control (untreated cells) has been established for the comparison of treated cells. In our test, the control shows 100 percent feasibility with the cell lines that were developed to evaluate anticancer activity [50]. The breast cancer cell line was treated against $5 \mathrm{mg} / \mathrm{ml} \mathrm{ZnO-QDs}$ and $0.5 \mathrm{mg} / \mathrm{ml} \mathrm{ZnO-BC}$ of varying concentrations ranging from 3.125$50 \mu \mathrm{g} / \mathrm{ml}$ and $25-500 \mu \mathrm{g} / \mathrm{ml}$ respectively. It was inspected from the test that there was decreased viability rate, ranging from $60-15 \%$ for $0.5 \mathrm{mg} / \mathrm{ml} \mathrm{ZnO-BC}$ and $45-5 \%$ for $5 \mathrm{mg} / \mathrm{ml} \mathrm{ZnO-QDs}$ which revealed a tenfold decrease in cell viability with less concentration scale for $5 \mathrm{mg} / \mathrm{ml}$ of ZnO-QDs when compared with that of $0.5 \mathrm{mg} / \mathrm{ml} \mathrm{ZnO-BC}$. Phase-contrast microscopy images were shown in figure $9 \mathrm{a} \& 9 \mathrm{~b}$ which also distinctly supports the percentage viability of cells for ZnO-BC and ZnO-QDs. Therefore, the prepared ZnOQDs exhibit more biocompatibility when compared to ZnO-BC [44]. The ZnO-QDs treated cells showed more strain with that of $\mathrm{ZnO}-\mathrm{BC}$ due to the reduced particle size and presence of green materials (C.roseus\& A.vera) act as a rich carbon sources for the synthesis of ZnO-QDs which in turn are responsible for the anticancer activity and due to its penetrating property against breast cancer cells it can be used as an efficient anticancer drug.

\subsection{Hemocompactability}

Haemolytic assay of ZnO-QDs was checked to test its blood compatibility. From the quantitative assessment of $\mathrm{Hgb}$ and furthermore, from the actual perception the test was directed to assess the toxicity of synthesized $5 \mathrm{mg} / \mathrm{ml} \mathrm{ZnO}-Q D s$ at various concentrations, i.e., 50, 100, 150, 200, and $250 \mu \mathrm{g} / \mathrm{mL}$ (Fig. 10), it is prominent that the OD value for haemolysis was significantly higher with $250 \mu \mathrm{g} / \mathrm{ml}$, while just slight haemolysis was seen with $50 \mu \mathrm{g} / \mathrm{ml}$ rather than the negative control. The positive control caused the most hemolysis. According to ASTM (American Society for Testing and Materials Designation), which is standard practise for assessing the hemolytic properties of materials. Which indicates that hemolysis of less than $2 \%$ is considered non-hemolytic, $2-5 \%$ is considered somewhat hemolytic, and $>5 \%$ is considered hemolytic $[42,50]$. As a result, the results of $5 \mathrm{mg} / \mathrm{ml} \mathrm{ZnO-QDs} \mathrm{met} \mathrm{the}$ material standard of Hemolysis.

\section{Conclusion}


We, for the first time, have prepared and reported ZnO-QDs derived from bionanocomposite ZnO-BC by adapting microwave-assisted method without using any toxic chemicals. Also, ZnO-QDs where optimized using BBD of RSM to obtain the optimum reaction conditions of concentration value of ZnO-NPs, $A$.vera and $C$. roseus. Under the optimal conditions, that is, the concentration value of ZnO-NPs, A.vera, and $C$. roseus values was fixed at $0.5 \%, 1 \mathrm{~g}$ and $0.5 \mathrm{ml}$, respectively. The obtained ZnO-QDs have a high absorbance at $330 \mathrm{~nm}$ which was in contrast to that of characterization results obtained.Low concentration range of $\mathrm{ZnO}-\mathrm{QD}$ s revealed a favourablecytotoxicity when compared to ZnO-BC. Fromthese results, it can be concluded that due to the surface penetration property of ZnO-QDs (C. roseus\&A. vera) it could act as a new type of fluorescence probe that may act as a nano-carrierand can be known tothe nano-medical worldwide market after finishing its clinical preliminary and provide promising potential in the field ofbreast cancer treatment research.

\section{Declarations}

\section{Acknowledgements}

This research did not receive any specific grant from funding agencies in the public, commercial, or notfor-profit sectors.

\section{Conflicts of interest}

The authors hereby declare no conflicts of interest.

\section{References}

[1] Kavitha Shivaji, Suganya Mani, Ponnusamy Ponmurugan, Catherine Suenne De Castro,

Matthew Lloyd Davies, Mythili Gnanamangai Balasubramanian, and Sudhagar Pitchaimuthu, GreenSynthesis-Derived CdS Quantum Dots Using Tea Leaf Extract: Antimicrobial, Bioimaging, and Therapeutic Applications in Lung Cancer Cells. ACS Appl. Nano Mater 1, 1683-169 (2018).

DOI:10.1021/acsanm.8b00147.

[2] NingxiaoGao, Libing Huang, Tianya Li, Jinghui Song, Hengwei Hu, Yong Liu , Seeram Ramakrishna. Application of carbon dots in dye-sensitized solar cells: A review. J. Appl. Polym. Sci 136,48443(2019). DOI: 10.1002/APP.48443.

[3] XiaohuiGao, Cheng Du, ZhihuaZhuang and Wei Chen, Carbon quantum dot-based nanoprobes for metal ion detection, J.Mater. Chem. C 4,6927-6945(2016). DOI: 10.1039/C6TC02055K.

[4] AlirezaValizadeh, HalehMikaeili, Mohammad Samiei, SamadMussaFarkhani, NosratalahZarghami, Mohammad kouhi et al, Quantum dots: synthesis, bioapplications, and toxicity, Nanoscale Res. Lett, 7,480(2012). Doi:10.1186/1556-276X-7-480. 
[5] Sen Liu , JingqiTian , Lei Wang , Yingwei Zhang , Xiaoyun Qin , YonglanLuoet al, Hydrothermal Treatment of Grass: A Low-Cost, GreenRoute to Nitrogen-Doped, Carbon-Rich, PhotoluminescentPolymerNanodots as an Effective Fluorescent Sensing Platform for Label-Free Detection of Cu(II) lons. Adv. Mater. 24(15),2037-41(2012). DOI: 10.1002/adma.201200164

[6] Shuo Liu, Yan-Mei Wang, Jie Han. Fluorescent Chemo sensors for Copper(II) Ion: Structure, Mechanism and Application, 32,78-103(2017).

http://dx.doi.org/doi:10.1016/j.jphotochemrev.2017.06.002.

[7] Caoxing Huang, Huiling Dong, Yan Su, Yan Wu, Robert Narron and QiangYong. Synthesis of Carbon Quantum Dot Nanoparticles Derived from Byproducts in Bio-Refinery Processfor Cell Imaging and In Vivo Bioimaging. Nanomaterials 9,387(2019). doi:10.3390/nano9030387.

[8] Zhezhu Nan, Changchun Hao, Xianggang Zhang, Hengyu Liu, Runguang Sun, Carbon quantum dots (CQDs) modified $\mathrm{ZnO} / \mathrm{CdS}$ nanoparticles based fluorescencesensor for highly selective and sensitive detection of $\mathrm{Fe}(\mathrm{III})$ 5,228,117717(2020). doi: 10.1016/j.saa.2019.117717.

[9]Hediyeh Sepahi Zavareh, Mehrab Pourmadadi, Ali Moradi, Fatemeh Yazdian, Meisam Omidi. Chitosan/carbon quantum dot/aptamer complex as a potentialanticancer drug delivery system towards the release of 5-fluorouracil, Int. J. Biol. Macromol, 165,1422-1430(2020).

https://doi.org/10.1016/j.jjbiomac.2020.09.166

[10] Rajarshi Bayan and Niranjan Karak. Photo-Assisted Synthesis of a Pd-Ag@CQDNanohybrid and Its Catalytic Efficiency in Promoting the Suzuki-Miyaura Cross-Coupling Reaction under Ligand-Free and Ambient Conditions. ACS Omega 2, 8868-8876(2017). DOI:10.1021/acsomega.7b01504.

[11] Joe Briscoe, Adam Marinovic, Marta Sevilla, Steve Dunn, and Magdalena Titirici. Biomass-Derived Carbon Quantum Dot Sensitizers for Solid-State Nanostructured Solar Cells.Angew. Chem. Int. Ed. 54, 7(2015). DOI: 10.1002/anie.201409290.

[12] Bala subramanian Malaikozhundan, Baskaralingam Vaseeharan, Sekar Vijayakumar,Karuppiah Pandiselvi, Rajamohamed Kalanjiam, Kadarkarai Murugan et al. Biological therapeutics of Pongamiapinnata coated zinc oxide nanoparticles againstclinically important pathogenic bacteria, fungi and MCF-7 breast cancer cells. Microb. Pathog. 104,268-277(2017). DOI: 10.1016/j.micpath.2017.01.029.

[13] Nurettin Sahiner, Selin S. Suner, Mehtap Sahiner \& CoskunSilan. Nitrogen and Sulfur Doped Carbon Dots from Amino Acidsfor Potential Biomedical Applications.J. Fluoresc. 29(5),1191-1200(2019). DOI: 10.1007/s10895-019-02431-y.

[14] Sudheer Rai, Brijesh Kumar Singh, PrabhaBhartiya, Anu Singh, Hridyesh Kumar, P. K. Duttaand et al. Lignin derived reduced fluorescence carbon dots with theranosticapproaches: Nano-drug-carrier and bioimaging. J.Lumin, 190,492-503(2017). https://doi.org/10.1016/j.jlumin.2017.06.008 
[15] SalihaDinç, Meryem Kara, MeltemDemirel Kars, FatmanurAykül, HacerÇiçekci, Mehmet Akkuş. Biocompatible yogurt carbon dots: evaluation of utilizationfor medical applications. Appl. Phys. A 123,572(2017). DOI 10.1007/s00339-017-1184-y.

[16] RinkySha, S. Solomon Jones, Sushmee Badhulika. Controlled synthesis of platinum nanoflowers supported on carbon quantum dots as a highly effective catalyst for methanol electro-oxidation. Surf. Coat. Technol 12,400-408(2019). https://doi.org/10.1016/j.surfcoat.2018.12.127.

[17] MdRifatHasan, NepuSaha, Thomas Quaid and Toufiq Reza M. Formation of Carbon Quantum Dots via Hydrothermal Carbonization: Investigate the Effect of Precursors. Energies 14,986(2021). https://doi.org/10.3390/en14040986.

[18] Yujin Choi , Nichaphat Thongsai , Ari Chae , Seongho Jo , Eun Bi Kang ,PeerasakPaoprasert et al. Microwave-assisted synthesis of luminescent and biocompatiblelysine-based carbon quantum dots. J IndEngChem J. 47,329-335(2017). http://dx.doi.org/10.1016/j.jiec.2016.12.002.

[19] Huanhuan Xu, Lihe Yan, Vanthan Nguyen, Yang Yu,YanminXu. One-step synthesis of nitrogen-doped carbon nanodotsforratiometric $\mathrm{pH}$ sensing by femtosecond laser ablationmethod.Appl. Surf. Sci 414,238243(2017). https://doi.org/10.1016/j.apsusc.2017.04.092.

[20] Chao-Mujica FL, Garcia-Hernández L, Camacho-López S, Camacho-López M, Camacho-López MA, Reyes Contreras D et al. Carbon quantum dots by submerged arcdischarge in water: Synthesis, characterization, and mechanism of formation. J. Appl. Phys. 129,163301(2021). doi:

$10.1063 / 5.0040322$.

[21] Tomy Abuzairi, Mitsuru Okada, Yohei Mochizuki, NjiRaden Poespawati,Retno Wigajatri Purnamaningsih, Masaaki Nagatsu. Maskless functionalization of a carbon nanotubedot array biosensor using an ultrafine atmosphericpressure plasma jet.Carbon 89, 208-216(2015).

https://doi.org/10.1016/j.carbon.2015.03.015.

[22] Xianfeng Zhang, Jingbo Lu, Xiaoli Zhou, ChunyanGuo, Chuanhu Wang. Rapid microwave synthesis of $\mathrm{N}$-doped carbon nanodots with highfluorescence brightness for cell imaging and sensitive detection of iron(III). Opt. Mater 64(2017). http://dx.doi.org/10.1016/j.optmat.2016.11.026.

[23] Asim Ali Yaqoob, Hilal Ahmad, TabassumParveen, Akil Ahmad, Mohammad Oves,lqbal M. let al.Recent Advances in Metal DecoratedNanomaterials and Their VariousBiological Applications: A Review. Front. Chem 8,34(2020). doi: 10.3389/fchem.2020.00341.

[24] Abinaya C, ManjulaDeviR,SureshP,BalasubramanianN,Muthaiya N, Kannan ND, et al. Antibacterial and anticancer activity of hydrothermally synthesized zincoxide nanomaterials using natural extracts of neem, pepper and turmeric as solvent media. NanoExpress 1,010029(2020). https://doi.org/10.1088/2632-959X/ab8a76. 
[25] Kanika Dulta, Gözde Koşarsoy Ağçeli, Parveen Chauhan, Rohit Jasrotia, Chauhan PK. A Novel Approach of Synthesis Zinc Oxide Nanoparticles by Bergeniaciliata Rhizome Extract: Antibacterial and Anticancer Potential 31(5) (2021) J Inorg OrganometPolym Mater. DOI:10.1007/s10904-020-01684-6

[26] Carol E. DeSantis, Freddie Bray, Jacques Ferlay, JoannieLortet-Tieulent, Benjamin O. Anderson, and AhmedinJemal. International Variation in Female Breast Cancerlncidence and Mortality Rates.CancerEpidemiol Biomarkers Pre 24(10),1495-506(2015). doi: 10.1158/1055-9965.EPI-15-0535.

[27] Nida Nayyar Farshori, Ebtesam SaadAl-Sheddi, Mai Mohammad Al Oqail,JavedMusarrat, Abdulaziz Ali Al-Khedhairy et al. Anticancer Activity of Petroselinumsativum Seed Extracts on MCF-7 Human Breast Cancer Cells. Asian Pac J Cancer Prev 14(10),5719-723(2013).

DOI:http://dx.doi.org/10.7314/APJCP.2013.14.10.5719

[28] Jayanta Kumar Patra , Gitishree Das, Leonardo Fernandes Fraceto, EstefaniaVangelie Ramos Campos Maria del Pilar Rodriguez-Torres, Laura Susana Acosta-Torres et al. Nano based drug delivery systems:recent developments and future prospects.J. Nanobiotechnology 16,71(2018). https://doi.org/10.1186/s12951-018-0392-8.

[29] Saba Ibrahim, Zahoor Ahmad, Muhammad ZeeshanManzoor, Muhammad Mujahid, Zahra Faheem\& Ahmad Adnan, Optimization for biogenic microbialsynthesis of silver nanoparticlesthrough response surfacemethodology, characterization,their antimicrobial, antioxidant,and catalytic potential, Scientific Reports 11,770(2021). https://doi.org/10.1038/s41598-020-80805-0

[30] Hend M. H. Al-Kordy, Soraya A. Sabry\& Mona E. M. Mabrouk. Statistical optimization of experimental parameters for extracellular synthesis of zincoxide nanoparticles by a novel haloalaliphilic Alkali bacillus sp.W7. Scientific Reports 11,10924(2021). | https://doi.org/10.1038/s41598-021-90408-y.

[31] Mustafa Camas, FatihCelik, Anil Sazak Camas, and HasanBarisOzalp.Biosynthesis of gold nanoparticles using marine bacteria and Box-Behnkendesign optimization.PARTICUL SCI TECHNOL 1548-0046(2017). https://doi.org/10.1080/02726351.2017.1287794.

[32] Rong Ma, Pei-Jiang Zhou, Hong-Ju Zhan, Chi Chen, Yu-NingHe.Optimization of microwave-assisted synthesis of high-quality $\mathrm{ZnSe} / \mathrm{ZnS}$ core/shell quantum dots using response surface methodology. Optics Communications 291,476-481(2013). http://dx.doi.org/10.1016/j.optcom.2012.11.030

[33] Xin Li, KandasamyVinothini, Thiyagarajan Ramesh, Mariappan Rajan \& AndyRamu. Combined photodynamic-chemotherapy investigation of cancer cells using carbonquantum dot-based drug carrier system. Drug Delivery 27(1),791-804(2020). https://doi.org/10.1080/10717544.2020.1765431.

[34] GanesanMuthusankar, RamadhassKeerthika Devi, GopalakrishnanGopu. Nitrogen-doped carbon quantum dots embedded $\mathrm{CO}_{3} \mathrm{O}_{4}$ with multiwall carbonnanotubes: An efficient probe for the simultaneous determination of anticancer andantibiotic drugs. BiosensBioelectron 15,150,111947(2020). doi: 10.1016/j.bios.2019.111947. 
[35] Elaine S.M. Cutrim, André A.M. Vale, DaniloManzani, HernaneS. Barud, Enrique Rodríguez-Castellón, Ana P.S.A. Santos, AnaC.S. Alcântara. Preparation, characterization and in vitro anticancer performance of nanoconjugate based on carbon quantum dots and

5-Fluorouracil. Materials Science and Engineering: C 120,111781(2021).

https://doi.org/10.1016/j.msec.2020.111781

[36] Zahra Fakhroueian, Alireza Mozafari Dehshiri, Fatemeh Katouzian, Pegah Esmaeil zadeh.In vitro cytotoxic effects of modified zinc oxide quantumdots on breast cancer cell lines (MCF7), colon cancer cell lines (HT29) and various fungi. JNanopart Res 16,2483(2014). DOI 10.1007/s11051-014-2483-2.

[37] YuanQ ,Hein S, Misra RDK. New generation of chitosan-encapsulated ZnO quantum dots loaded with drug:Synthesis, characterization and in vitro drug delivery response. ActaBiomaterialia 6,27322739(2010). doi:10.1016/j.actbio.2010.01.025.

[38]Thanigaivelan Arumugham, Manikandan Alagumuthu, Reshika Gnanamoorthi Amimodu,Sathishkumar Munusamy, SathiyanarayananKulathulyer. A sustainable synthesis of green carbon quantum dot (CQD) fromCatharanthus roseus (white flowering plant) leaves and investigationof its dual fluorescence responsive behavior in multi-ion detectionand biological applications. Sustain. Mater. Technol 23,00138(2020).

[39] Yanjie Yang, ZhenhuaSong,Weixia Wu, AoXu, ShuangyuLvandShaopingJi. ZnO Quantum Dots Induced Oxidative Stress and Apoptosis in HeLa and HEK-293T Cell Lines 11,13(2020). https://doi.org/10.3389/fphar.2020.00131.

[40] David K. Liscombe, Sarah E. O'Connor. A virus-induced gene silencing approach to understanding alkaloid metabolismin Catharanthus roseus.Phytochemistry 72,1969-1977(2011). doi:10.1016/j.phytochem.2011.07.001.

[41] Lei Yang, Han Wang, Yuan-gang Zu, Chunjian Zhao, Lin Zhang, Xiaoqiang Chen, et al. Ultrasoundassisted extraction of the three terpenoidindole alkaloids vindoline,catharanthineand vinblastine from Catharanthus roseus using ionic liquidaqueoussolutions.Chem. Eng. Sci 172,705-712(2011). doi:10.1016/j.cej.2011.06.039.

[42] Sangeetha Aula, SamyukthaLakkireddy, Swamy AVN, AtyaKapley, Kaiser Jamil, NarasingaRao Tata and KaliyanHembram. Biological interactions in vitro of zinc oxidenanoparticles of different characteristics.Materials Research Express 1, 035041(2014). doi:10.1088/2053-1591/1/3/035041

[43] Elumalai K. Velmurugan S. Green synthesis, characterization and antimicrobial activities of Zinc Oxide nanoparticles from the leaf extract of Azadirachta indica (L.) Applied Surf. Sci 3,176(2015). http://dx.doi.org/10.1016/j.apsusc.2015.03.176. 
[44] Leila Florento, Ronald Matias, Elena Tuaño, Katherine Santiago, Frederick dela Cruz, Alexander Tuazon.Comparison of Cytotoxic Activity of Anticancer Drugs against Various Human Tumor Cell Lines Using In Vitro Cell-Based Approach. Int. J. Biomed 8(1)(2012).

[45] NehaBajwa, Neelesh Kumar Mehra, Keerti Jain \&Narendra Kumar Jain. Targeted anticancer drug delivery through anthracycline antibiotic bearing functionalized quantum dots.Artificial Cells, Nanomedicine, and Biotechnology 44(7), 774-1782(2016). DOI:

10.3109/21691401.2015.1102740.

[46] Cristina Fornaguera , Gabriela Calderó, Montserrat Mitjans, Maria PilarVinardell, Conxita Solans, Christine Vauthier. Interaction of PLGA nanoparticles with blood components: protein adsorption, coagulation, activation of the complement system and hemolysis studies 7(14),6045-58(2015). doi: 10.1039/c5nr00733j.

[47] Tülin Arasoglu, Serap Derman and Banu Mansuroglu. Comparative evaluation of antibacterial activity of caffeic acid phenethyl ester and PLGA nanoparticle formulation by different methods.Nanotechnology 27,025103(2016). doi:10.1088/0957-4484/27/2/025103.

[48] Ishchenko AV, Shulgin BV, Vokhmintsev AS, Weinstein IA, Shalimov LN, Manko GN et al. Radiation optical effects in commercial SiO2 :Gefibers. Journal of Physics: Conference Series 552,012036(2014). doi:10.1088/1742-6596/552/1/012036.

[49] VajravathiLakkim, Madhava C. Reddy, Roja Rani Pallavali, KakarlaRaghavaReddy ,

ChVenkata Reddy, Inamuddin, et al. Green Synthesis of Silver Nanoparticles and Evaluation of Their Antibacterial Activity against Multidrug-Resistant Bacteria and Wound Healing Efficacy Using a Murine Model. Antibiotics 9,902(2020). doi:10.3390/antibiotics9120902.

[50] MuthukumarThangavelu\&AravinthanAdithan\&SastryThotapalliParvathaleswara\&Chamundeeswari Munusamy. Morphological Modification of Carbon Nanoparticles after Interacting with Methotrexate as a Potential Anticancer Agent. Pharm Res 35,184(2018). https://doi.org/10.1007/s11095-018-2468-4.

\section{Scheme}

Please see the Supplementary Files for the Scheme 1.

\section{Figures}




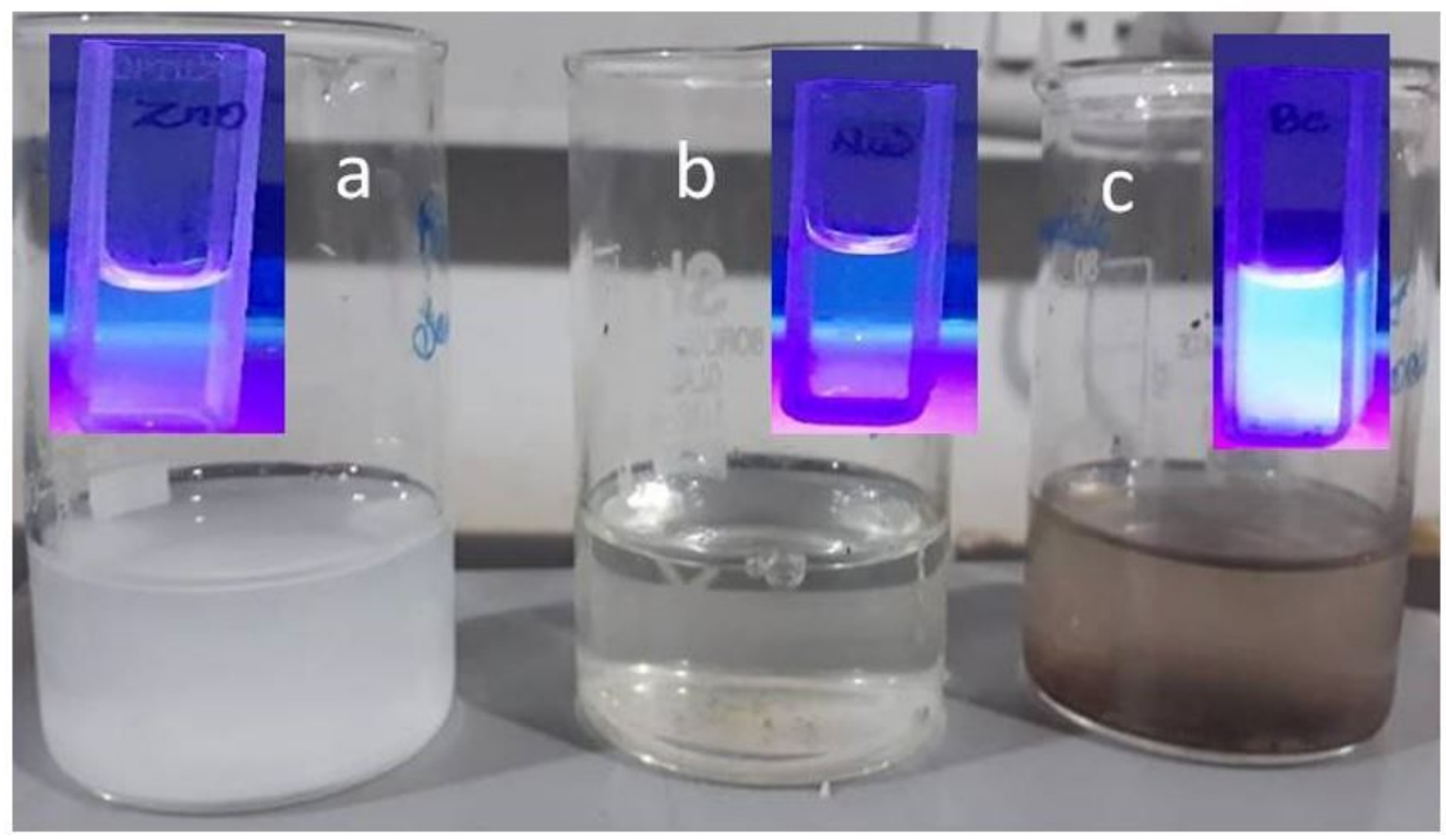

Figure 1

UV trans illuminator observation a) Commercial ZnO b) Synthesized ZnO c) Synthesized ZnO-QDs
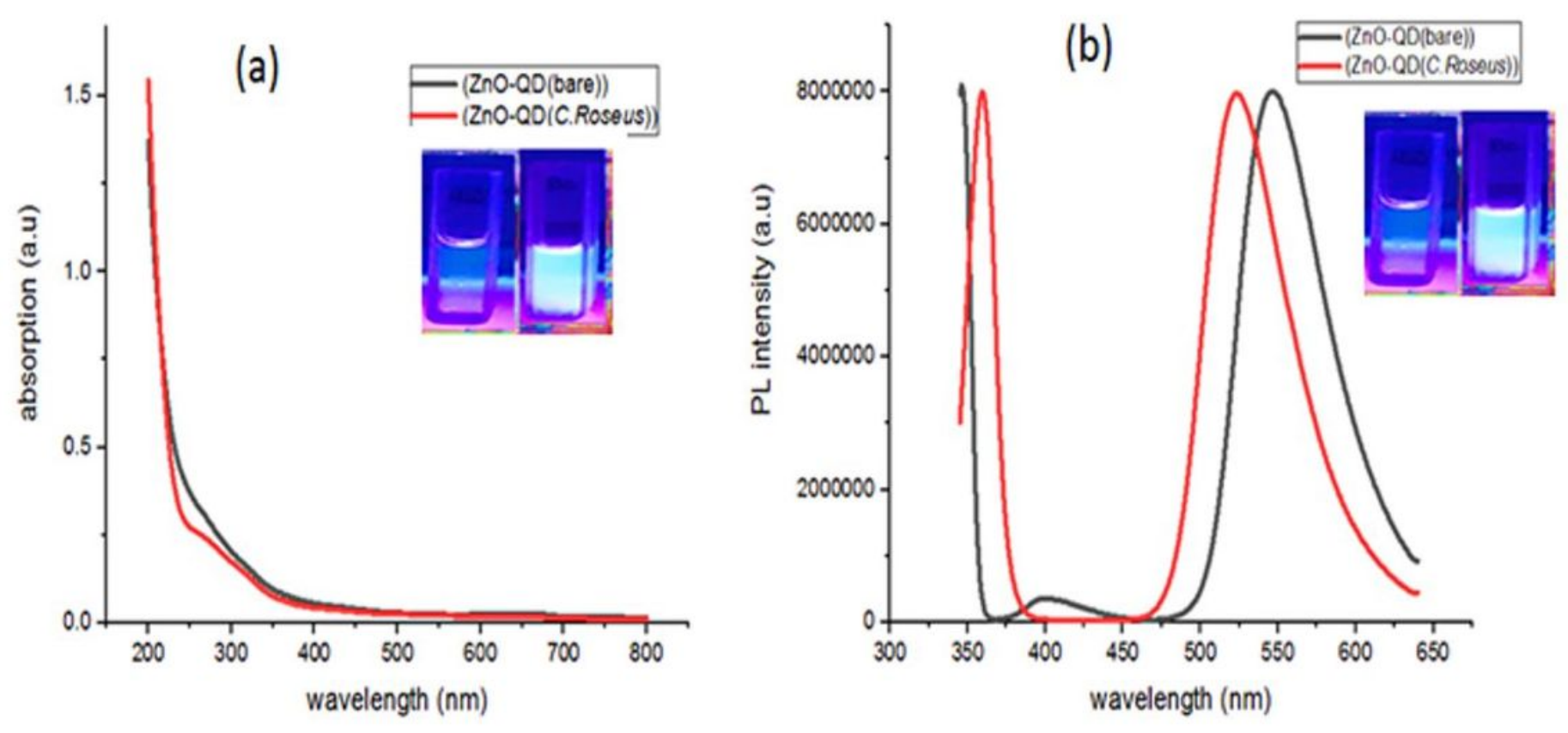

Figure 2 
(a) UV-Vis spectra of ZnO-QDs from Catharanthus roseus leaves and bare ZnO (b) PL excitation spectrum for excitation wavelength of $330 \mathrm{~nm}$. Inset shows the digital pictures under normal light (left) and UV (right) radiation.

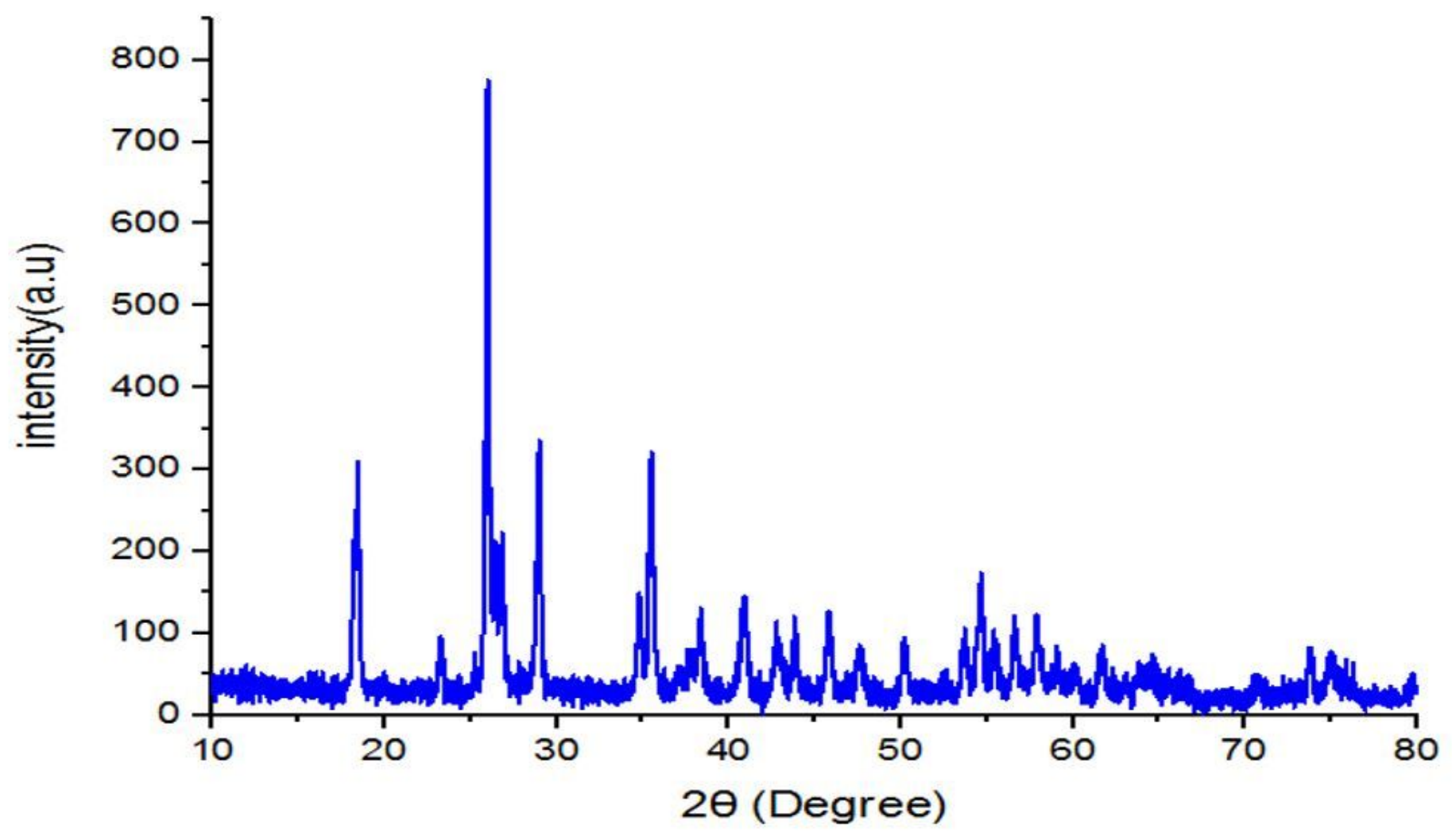

Figure 3

X-ray diffraction pattern of $\mathrm{ZnO}-\mathrm{BC}$ 


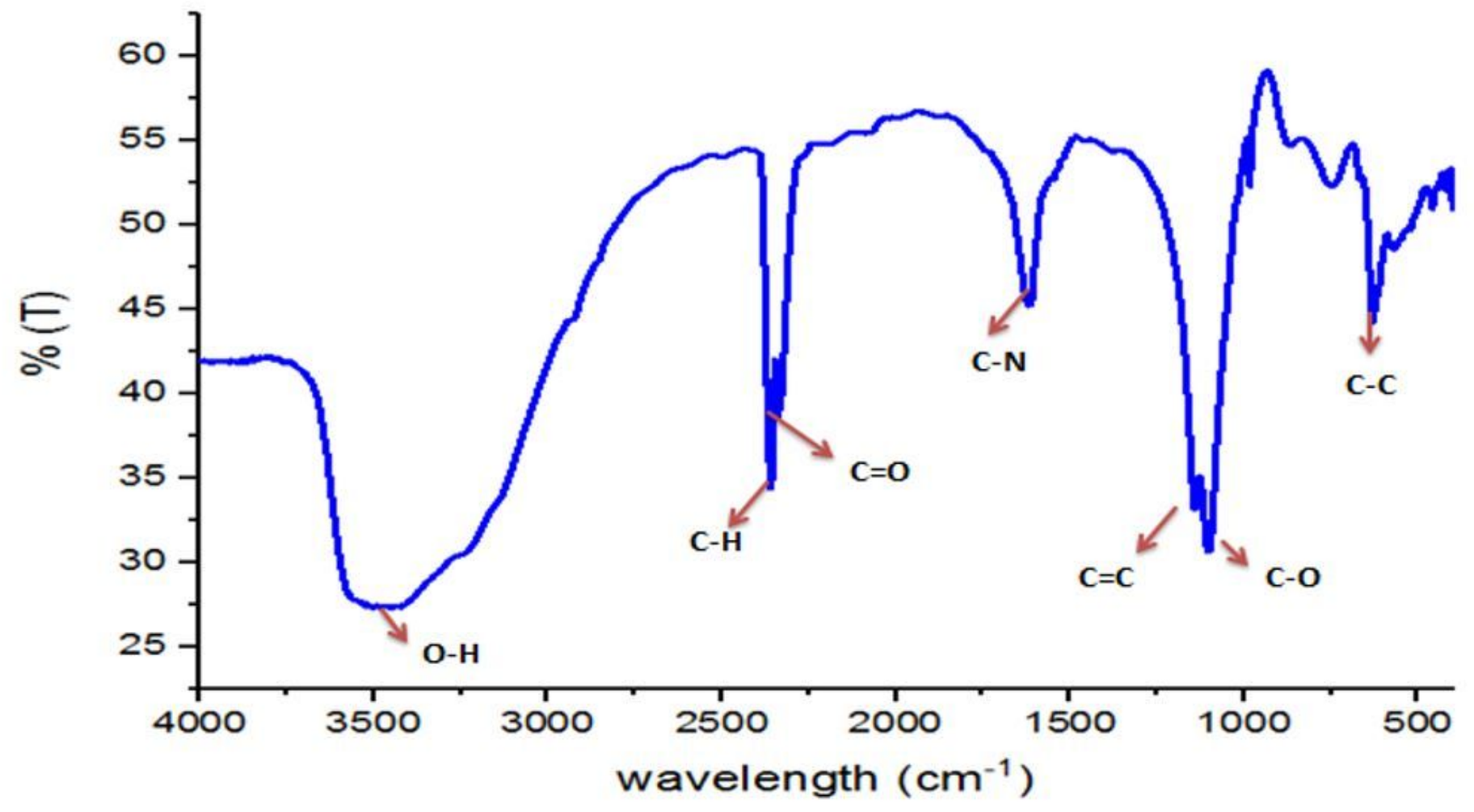

Figure 4

Fourier transform infrared spectra showing the functional group of $\mathrm{ZnO}-\mathrm{BC}$
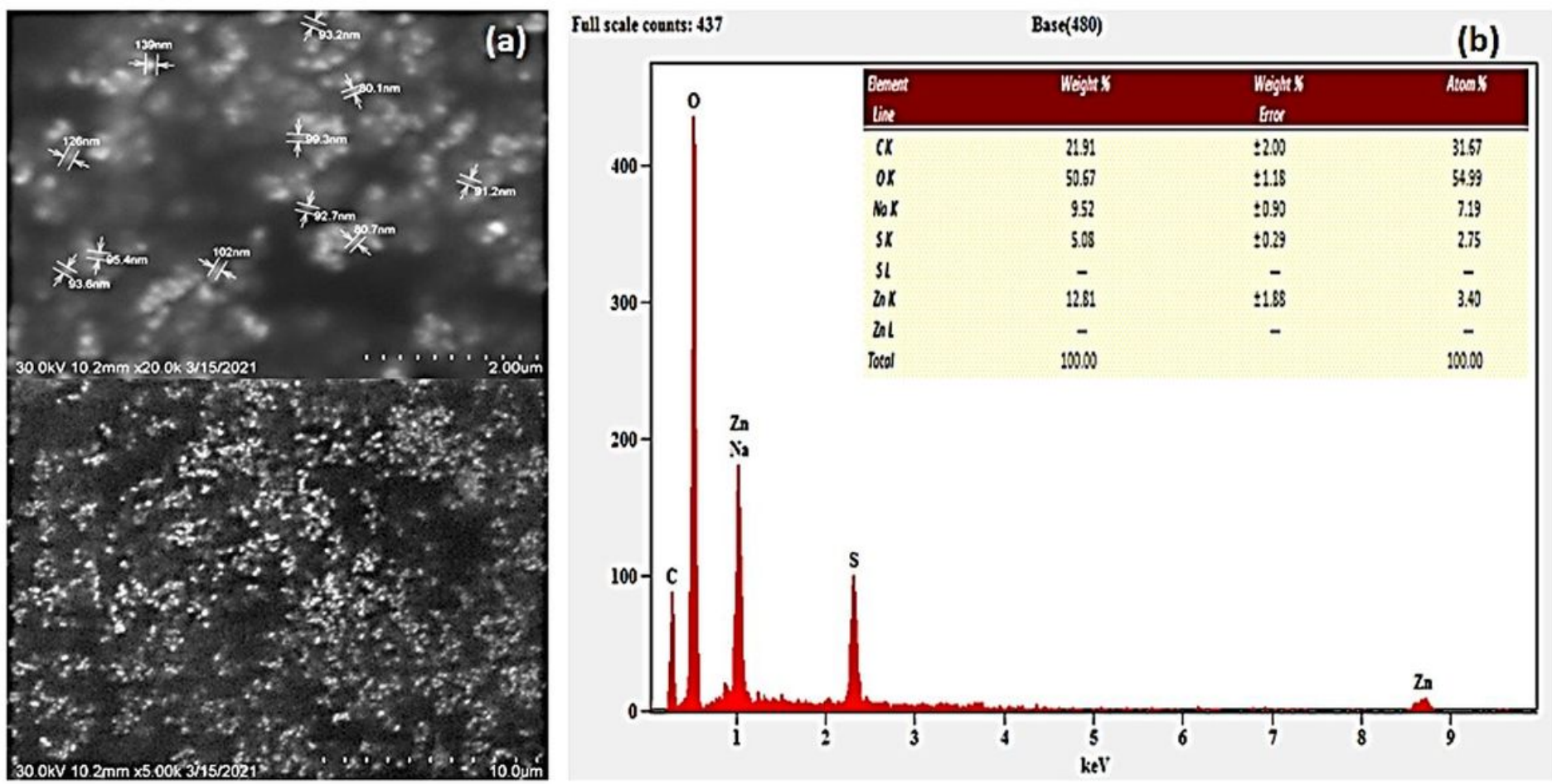

Figure 5 
(a)Scanning electron micrograph (SEM) of ZnO-BC (b) Energy dispersive X-ray (EDX) analysis of ZnO-BC

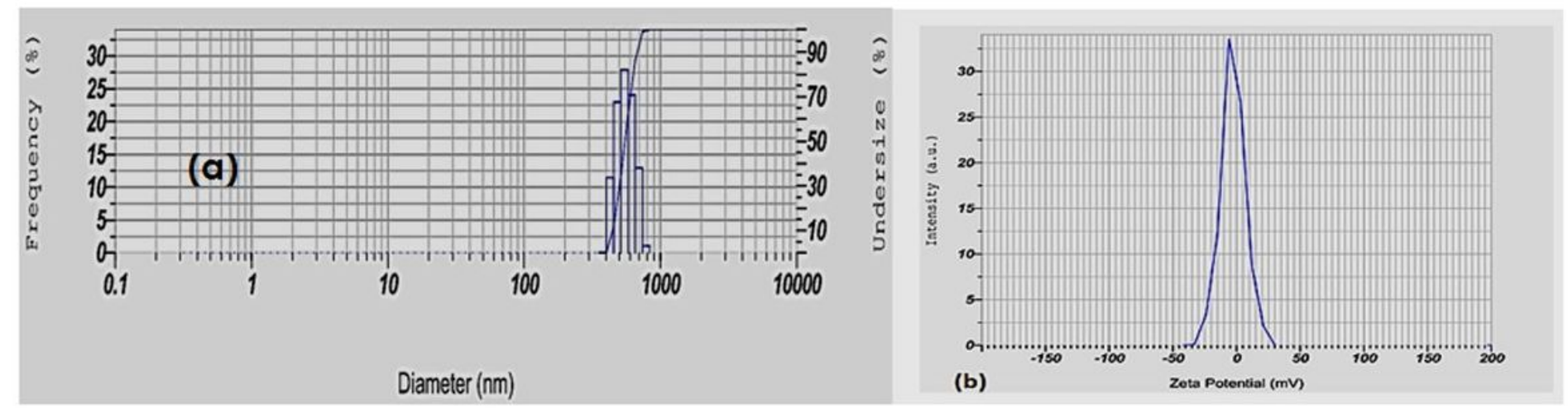

\section{Figure 6}

(a) Particle size distribution of ZnO-BC (b) Zeta Potential measurements of ZnO-BC

\section{Figure 7}

3D graphics for optimization of response surface by plotting absorbance versus concentration of (a) ZnO-NP (ml) and A. vera (g), (b) ZnO-NP (ml) and C. roseus (ml), (c) A. vera (g) and C. roseus (ml) obtained from ZnO-QDs using BBD of RSM

(a)

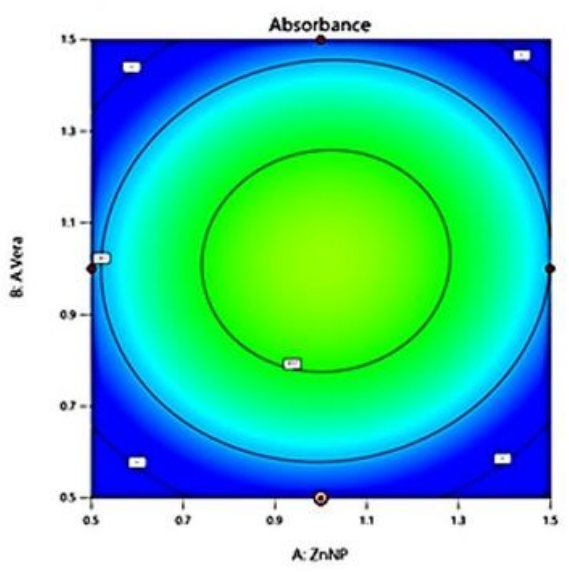

(b)

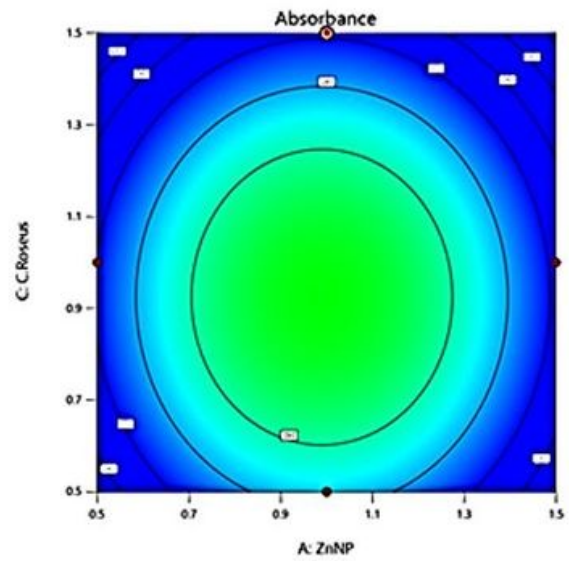

(c)

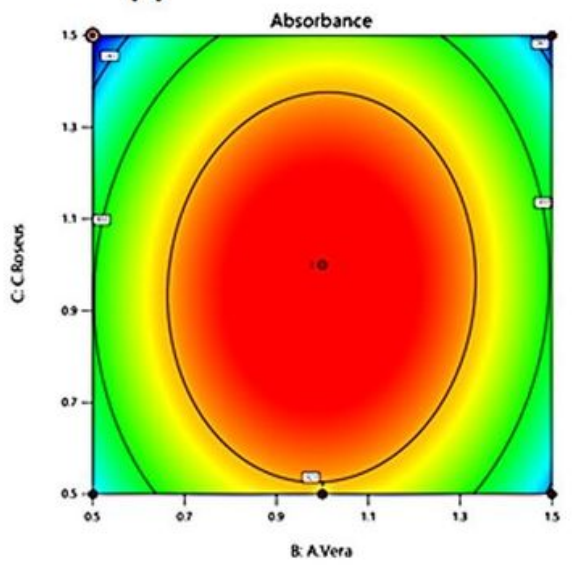

\section{Figure 8}

contour showing graphics by plotting absorbance versus concentration of (a) ZnO NPS (ml) and A. vera (g), (b) ZnO-NP ( $\mathrm{ml})$ and C. roseus $(\mathrm{ml})$, (c) A. vera $(\mathrm{g})$ and C . roseus $(\mathrm{ml})$ using BBD of RSM for investigation of interacted parameters belonging to the synthesis of $\mathrm{ZnO}-\mathrm{QDs}$. 


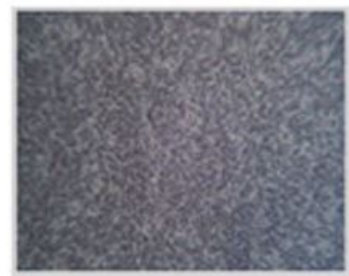

(a)

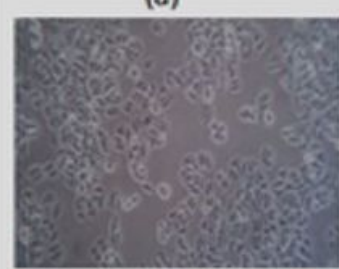

(d)

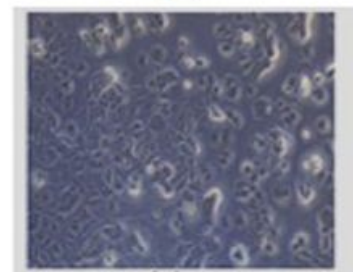

(a)

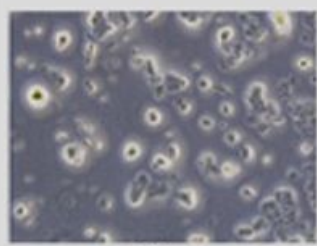

(d)

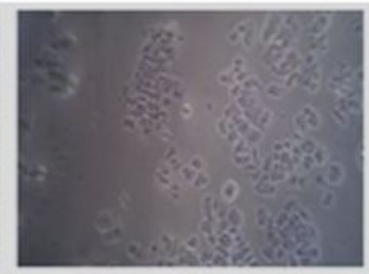

(b)

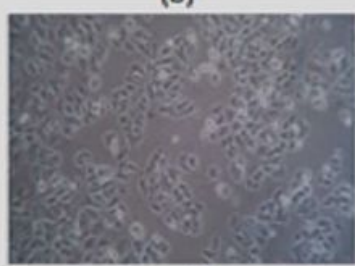

(e)

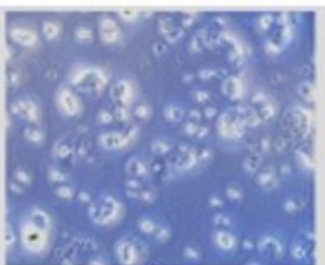

(b)

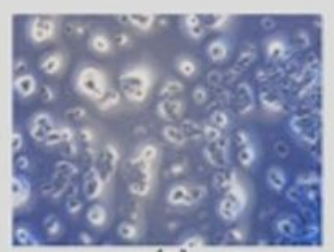

(e) (c)

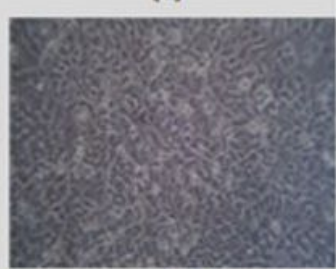

(f)

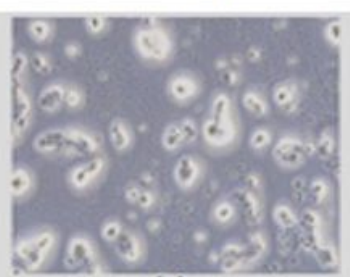

(c)

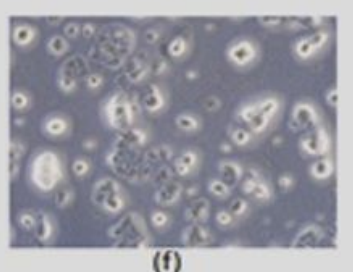

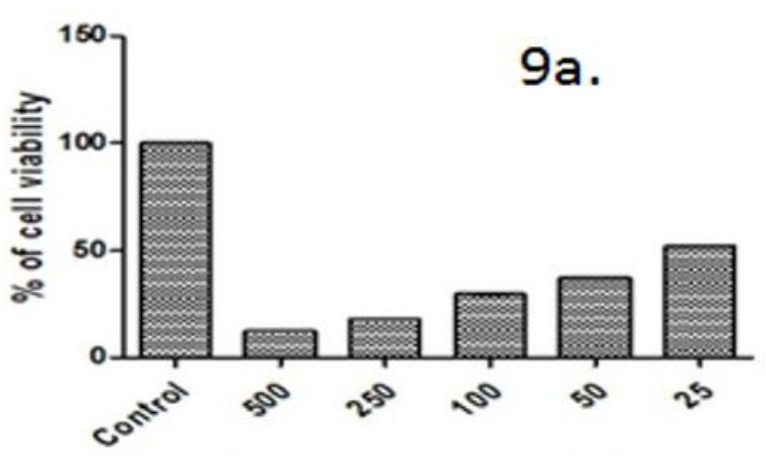

Concentrations in $\mu \mathrm{g} / \mathrm{ml}$



Concent rations in $\mu \mathrm{g} / \mathrm{ml}$

\section{Figure 9}

(a \& b). Cell viability and MTT assay images using phase contrast microscopy of MCF-7 cells treated against ZnO-BC and ZnO-QDs of concentration ranges :9a -ZnO-BC (a) control (b) $500 \mu \mathrm{g} / \mathrm{ml}$ (c) 250 $\mu \mathrm{g} / \mathrm{ml}$ (d) $100 \mu \mathrm{g} / \mathrm{ml}$ (e) $50 \mu \mathrm{g} / \mathrm{ml}$ (f) $25 \mu \mathrm{g} / \mathrm{ml}$; 9b -ZnO-QDs (a) control (b) $50 \mu \mathrm{g} / \mathrm{ml}$ (c) $25 \mu \mathrm{g} / \mathrm{ml}$ (d) 12.5 $\mu \mathrm{g} / \mathrm{ml}$ (e) $6.25 \mu \mathrm{g} / \mathrm{ml}$ (f) $3.125 \mu \mathrm{g} / \mathrm{ml}$ respectively.
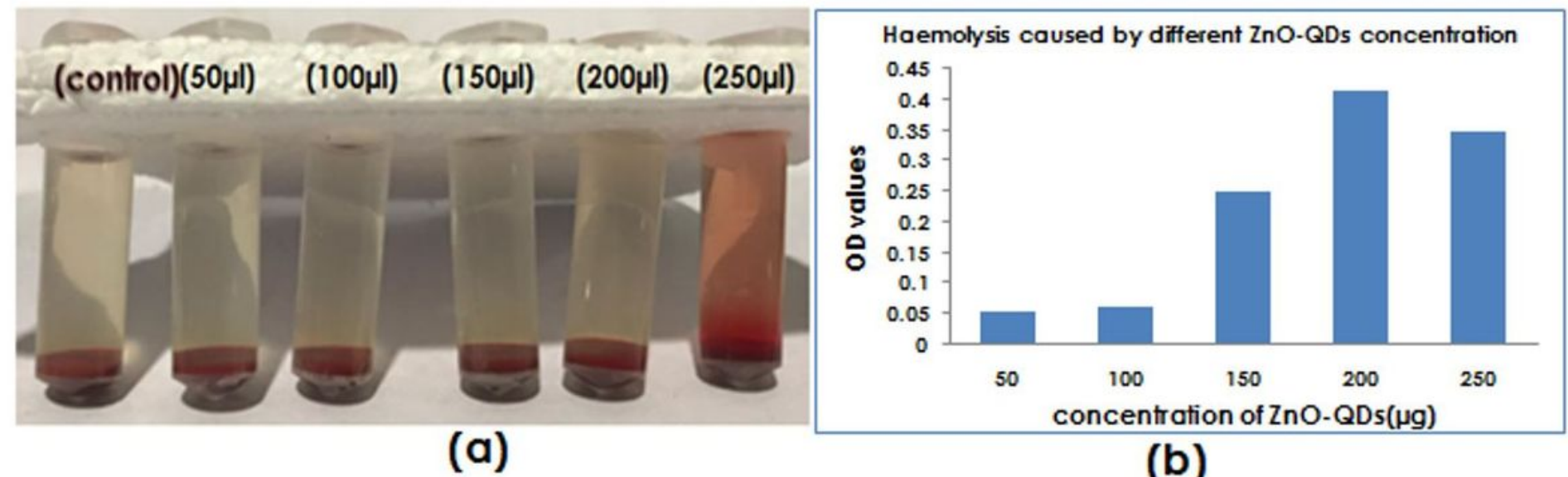

(b) 
(a) Haemolytic analysis image showing plasma from human blood sample incubated with ZnO-QDs (b) Haemolysis caused by different ZnO-QDs concentrations

\section{Supplementary Files}

This is a list of supplementary files associated with this preprint. Click to download.

- graphicsabstract.jpg

- scheme1.jpg

- SupplementaryData.docx 